\title{
Adhesion and cytoplasmic extension of Xylotrechus pyrrhoderus (Coleoptera; Cerambycidae) hemocytes induced by 20 -hydroxyecdysone and juvenile hormone in vitro
}

\author{
Keita Hoshino, Tsuyoshi HiraOKa and Kikuo IwABUCHI* \\ Faculty of Agriculture, Tokyo University of Agriculture and Technology; Fuchu, Tokyo 183-8509, Japan
}

(Received 3 September 2003; Accepted 14 November 2003)

\begin{abstract}
Insect larval hemocytes change their morphology and function during metamorphosis. However, the mechanisms driving the timing of these changes and the coordination with other premetamorphic events largely remain unclarified. With advancing stages of the beetle Xylotrechus pyrrhoderus prepupal development, the cell density of hemocytes decreased and adherent cells increased when the hemocytes were transferred into basal medium. The response of hemocytes from mature larvae before the prepupal stage to 20-hydroxyecdysone (20E) and juvenile hormone III (JH) was increased adhesion and morphological change; adherent cells accounted for $36.0 \%$ and $15.0 \%$ of cells in the 20E- and $\mathrm{JH}$-supplemented media, respectively, but only $8.5 \%$ of cells in basal medium. Moreover, $60.2 \%$ and $53.0 \%$ of the adherent cells changed to spindle-shaped cells in $20 \mathrm{E}$ and $\mathrm{JH}$ treatment, respectively, in contrast with $8.1 \%$ in the control. The responses of hemocytes to $20 \mathrm{E}$ and $\mathrm{JH}$ were dose-dependent, showing stronger responses at concentrations of $10^{-6} \mathrm{M}$ or more. The extended spindle-shaped cells with longer cytoplasmic extension increased to $30.9 \%$ in media supplemented with both $20 \mathrm{E}$ and $\mathrm{JH}$, compared with $9.7 \%$ for $20 \mathrm{E}$ alone and $3.6 \%$ for $\mathrm{JH}$ alone, suggesting that these two hormones act synergistically. The JH-related compounds, all-trans retinoic acid and farnesol, had no effect. The spindle-shaped cells were also observed at the same level as 20E-treated cells in non-treated cells after the third day of the prepupa stage when ecdysteroid titer is presumably high. These results indicate that the hemocytes of $X$. pyrrhoderus larvae are responsive to both $20 \mathrm{E}$ and $\mathrm{JH}$.
\end{abstract}

Key words: Xylotrechus pyrrhoderus; hemocyte; 20-hydroxyecdysone; juvenile hormone

\section{INTRODUCTION}

Most insect hemocytes have a phagocytic function against tissue debris resulting from developmental processes as well as foreign substances in their immune systems (Wigglesworth, 1959). Body structures and physiological systems change drastically during metamorphosis in holometabolous insects, and hemocytes play a crucial role of scavenging. The important role of insect hemocytes in metamorphosis accounts for some reports on their correlation with basement membrane formation (Wigglesworth, 1973), fat body dissociation (Kurata et al., 1989), and wing maturation (Nardi and Miklasz, 1989; Kiger et al., 2001; Nardi et al., 2001). In holometabolous insects, hemocyte density peaks in the prepupal period and declines rapidly during pupation (Arnold, 1952; Jones, 1956; Nittono, 1960). In lepidopteran and dipteran insects, pupal-specific granulocytes appear simulta- neously and adhere to various organs during pupation (Jones, 1956; Akai, 1969; Nardi et al., 2001). In the dipteran insect Sarcophaga peregrina, pupal hemocytes participate in the dissociation of larval fat bodies by secreting cathepsin B (Kurata et al., 1989,1992 ) and a $120-\mathrm{kDa}$ protein, a putative scavenger receptor, appears on the surface of prepupal granulocytes (Hori et al., 2000). In the lepidopteran insect Bombyx mori, cathepsin B-like protease mRNA is specifically expressed in prepupal and pupal granulocytes and plasmatocytes $(\mathrm{Xu}$ and Kawasaki, 2001). The appearance of hemocytes at the prepupal stage is suggested to be regulated by ecdysteroid titer (Lanot et al., 2001; Nishikawa and Natori, 2001; Xu and Kawasaki, 2001). However, the hemocyte changes in the prepupal period for coleopteran insects have not been investigated.

Metamorphosis is regulated by the endocrine system (Nijhout, 1994); two major hormones, 20-

\footnotetext{
* To whom correspondence should be addressed at: E-mail: kikkuo@cc.tuat.ac.jp
} 
hydroxyecdysone (20E) and juvenile hormone $(\mathrm{JH})$, both regulate the commitment of the epidermis and imaginal disks at the end of the larval stage (Riddiford, 1976; Kremen and Nijhout, 1998; Nijhout, 1999). With regard to the association of hemocytes with these hormones, $20 \mathrm{E}$ activates the migration of plasmatocytes in Manduca sexta (Judy and Marks, 1971) and both 20E and JH activate discharges of hemocytes from hemopoietic organs in B. mori (Han et al., 1995). However, little is known about the effect of the endocrine system on circulating hemocytes of coleopteran insects during metamorphosis.

In this study, the primary changes in hemocytes during metamorphosis were examined in the coleopteran insect, Xylotrechus pyrrhoderus. Hormonal control of hemocytes was examined under in vitro conditions to analyze the direct effect of $20 \mathrm{E}$ and $\mathrm{JH}$ on the morphology of hemocytes obtained at varying stages including the late final instar and prepupa.

\section{MATERIALS AND METHODS}

Insects. Larvae of Xylotrechus pyrrhoderus (Coleoptera: Cerambycidae) taken off of vine shoots were kept individually in $35 \mathrm{~mm}$ plastic dishes (Falcon 1008, Becton Dickinson Labware, Franklin Lakes, NJ). Fully grown larvae weighing over $200 \mathrm{mg}$ were designated as late final instar larvae. Prepupae were distinguished by morphological characters of the head inclining downward, the swollen thoracic segments and the lost of ampullae, according to Duffy's criteria (Duffy, 1952). Prepupae moulted to pupae after 5 days. Late final instar larvae and prepupae were used in the experiment.

Culture medium and hormones. MGM450 medium (Mitsuhashi and Inoue, 1988) was used for hemocyte culture. 20-Hydroxyecdysone (20E), juvenile hormone III $(\mathrm{JH})$, all-trans retinoic acid and farnesol were purchased from Sigma Chemical Co. (St. Louis, MO) and dissolved in 100\% ethanol. Hormone solutions or an equivalent amount of $100 \%$ ethanol were added to the culture medium.

In vitro experiment. Larva or prepupa were surface-sterilized by a $0.1 \%$ solution of benzalkonium chlorides for $3 \mathrm{~min}$, twice with $70 \%$ ethanol for $3 \mathrm{~min}$, and then dried under a stream of clean air in a laminar-flow cabinet. Hemolymph was obtained by cutting off a dorsal ampulla of the sterilized insect and dropped into $500 \mu \mathrm{l}$ of culture medium placed in a $35 \mathrm{~mm}$ culture dish (Falcon 1008). The cell suspension was distributed into the wells of a 24-well plate (Falcon 3847, Becton Dickinson Labware, Oxnard, CA) in volumes of 70-100 $\mu$ l to provide approximately equal cell numbers. Fresh medium was added to bring the volumes to $400 \mu 1$ per well, followed by gentle pipetting to mix the hemolymph and medium. Cultures were sealed with parafilm (American National Can, Greenwich, CT) and incubated at $25^{\circ} \mathrm{C}$.

Cell morphology. The adhesive properties of hemocytes following 3 to $4 \mathrm{~h}$ of incubation in MGM450 medium were examined on not less than 100 hemocytes in three fields of view under phasecontrast microscopy. Adherence was defined as being tightly attached to the surface of the culture dish (Fig. 1c arrow). Morphological changes were categorized based on the length of the longest axis through the cell; the cells with diameters over $50 \mu \mathrm{m}$ were classified as "spindle-shaped cells" and the remarkably extended cells with diameters over $100 \mu \mathrm{m}$ were designated "extended spindleshaped cells". All observations were carried out under phase-contrast microscopy with magnification of 100, 160, 200 and $320 \times$.

Statistical analysis. All experiments were repeated at least five times except for the data shown in Fig. 5 which was repeated three times. Data were presented as means \pm standard errors. Statistical analysis of the results was performed using analysis of variance (ANOVA) following transformation of the percent values to arcsine.

\section{RESULTS}

\section{Cell density and adhesion}

Cell density and adhesion of hemocytes obtained from mature $X$. pyrrhoderus larvae were investigated daily from the late final instar to the last stage (day 5) of the prepupal stage. The cell density remained relatively constant $\left(1.7 \times 10^{6} \mathrm{cells} / \mathrm{ml}\right)$ until day 2 of the prepupal stage, and then decreased rapidly to $0.8 \times 10^{6}$ cells $/ \mathrm{ml}$ on day 4 (Table 1). Cell adhesion was found in $11.3 \%$ of hemocytes in culture medium of the late final instar larva. This rate increased during prepupal development, rising to over $60 \%$ on day 3 of the prepupal stage. The degeneration of fat body tissues was 
Table 1. Cell density of X. pyrrhoderus hemocytes and degenerated fat body cells during premetamorphic stages

\begin{tabular}{|c|c|c|c|}
\hline \multirow{2}{*}{ Developmental stage } & \multicolumn{2}{|c|}{ Hemocyte $^{\mathrm{a}}$} & \multirow{2}{*}{$\begin{array}{l}\text { Fat body cells } \\
\left(\times 10^{4} \text { cels } / \mathrm{ml}\right)\end{array}$} \\
\hline & $\begin{array}{c}\text { Cell density } \\
\left(\times 10^{6} \text { cells } / \mathrm{ml}\right)\end{array}$ & $\begin{array}{c}\text { Adherent cells } \\
(\%)\end{array}$ & \\
\hline Late final instar larva & $1.7 \pm 0.3 \mathrm{a}$ & $11.3 \pm 5.1 \mathrm{a}$ & 0 \\
\hline Prepupa day 1 & $2.1 \pm 0.3 \mathrm{a}$ & $20.4 \pm 7.3 \mathrm{a}$ & $0.3 \pm 0.2$ \\
\hline day 2 & $1.7 \pm 0.3 \mathrm{a}$ & $28.2 \pm 6.4 \mathrm{a}$ & $1.0 \pm 0.4$ \\
\hline day 3 & $1.2 \pm 0.3 \mathrm{~b}$ & $65.7 \pm 10.4 b$ & $2.0 \pm 0.7$ \\
\hline day 4 & $0.8 \pm 0.1 \mathrm{~b}$ & $62.6 \pm 8.1 \mathrm{~b}$ & $-\mathrm{b}$ \\
\hline day 5 & $0.9 \pm 0.2 \mathrm{~b}$ & $66.1 \pm 10.0 \mathrm{~b}$ & $ـ^{\mathrm{b}}$ \\
\hline
\end{tabular}

${ }^{\text {a }}$ Five larvae were used each day. Means \pm SE with different letters in the same line indicate significant difference $(p<0.01$, ANOVA).

${ }^{\mathrm{b}}$ Not examined.
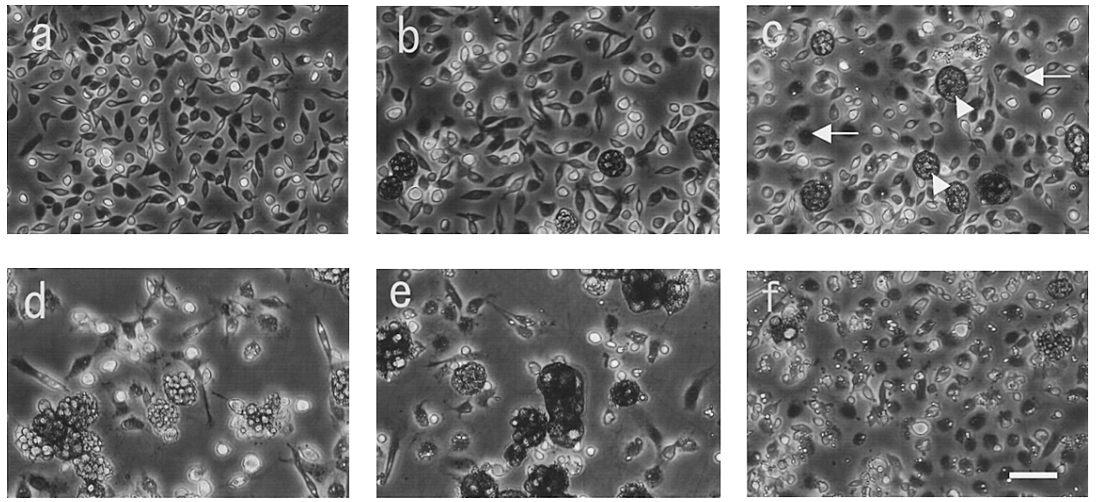

Fig. 1. X. pyrrhoderus hemocytes from late final instar larvae (a) and prepupal stage day 1 (b), 2 (c), 3 (d), 4 (e), and 5 (f) after $3 \mathrm{~h}$ in basal medium. Arrows indicate adherent cells and arrowheads indicate fat body cells. Photographed under phase-contrast microscopy $(\times 160)$. Bar indicates $50 \mu \mathrm{m}$.

first observed on day 1 and the cell lysation on day 4 of the prepupal stage (Fig. 1).

\section{Response of larval hemocytes to insect hor- mones}

Hemocytes from the late final instar larvae underwent changes in adherent properties and morphology in response to $10^{-6} \mathrm{M} 20$-hydroxyecdysone (20E) in vitro (Fig. 2). Cells adhered to the surface of the culture well from day 1 of culture $(27.5 \%)$. Approximately $36 \%$ of the cells were adherent by day 3, compared to only $8.5 \%$ in control (Fig. 3a). Adherent cells subsequently elongated and changed to spindle-shaped cell. Spindle-shaped cells accounted for $24.1 \%$ of the adherent cells 1 day after $20 \mathrm{E}$ treatment, and then gradually increased to over $50 \%$ on day 3 , in contrast with $18.1 \%$ in control (Fig. 3b). The larval hemocytes responded to $20 \mathrm{E}$ in a dose-dependent manner, showing response at a concentration of approximately $10^{-7} \mathrm{M}$ and reaching a plateau at $10^{-6} \mathrm{M}$ or more (Fig. 4).

The larval hemocytes also showed a slight increase in adherent cells in response to juvenile hormone III (JH; Figs. 2, 3a). Subsequent morphological changes occurred in a manner similar to that observed with $20 \mathrm{E} ; 53.0 \%$ of the cells became spindle-shaped on day 3 (Fig. 3b). The hemocyte adhesion induced by $\mathrm{JH}$ rose in a dose-dependent manner, although the maximum response (19.3\%) was lower than that for 20E (Fig. 4). Half of the adherent cells underwent cytoplasmic extension to form spindle-shaped morphologies in the presence of JH.

Among the spindle-shaped cells, some cells had long axis lengths of over $100 \mu \mathrm{m}$. When larval he- 


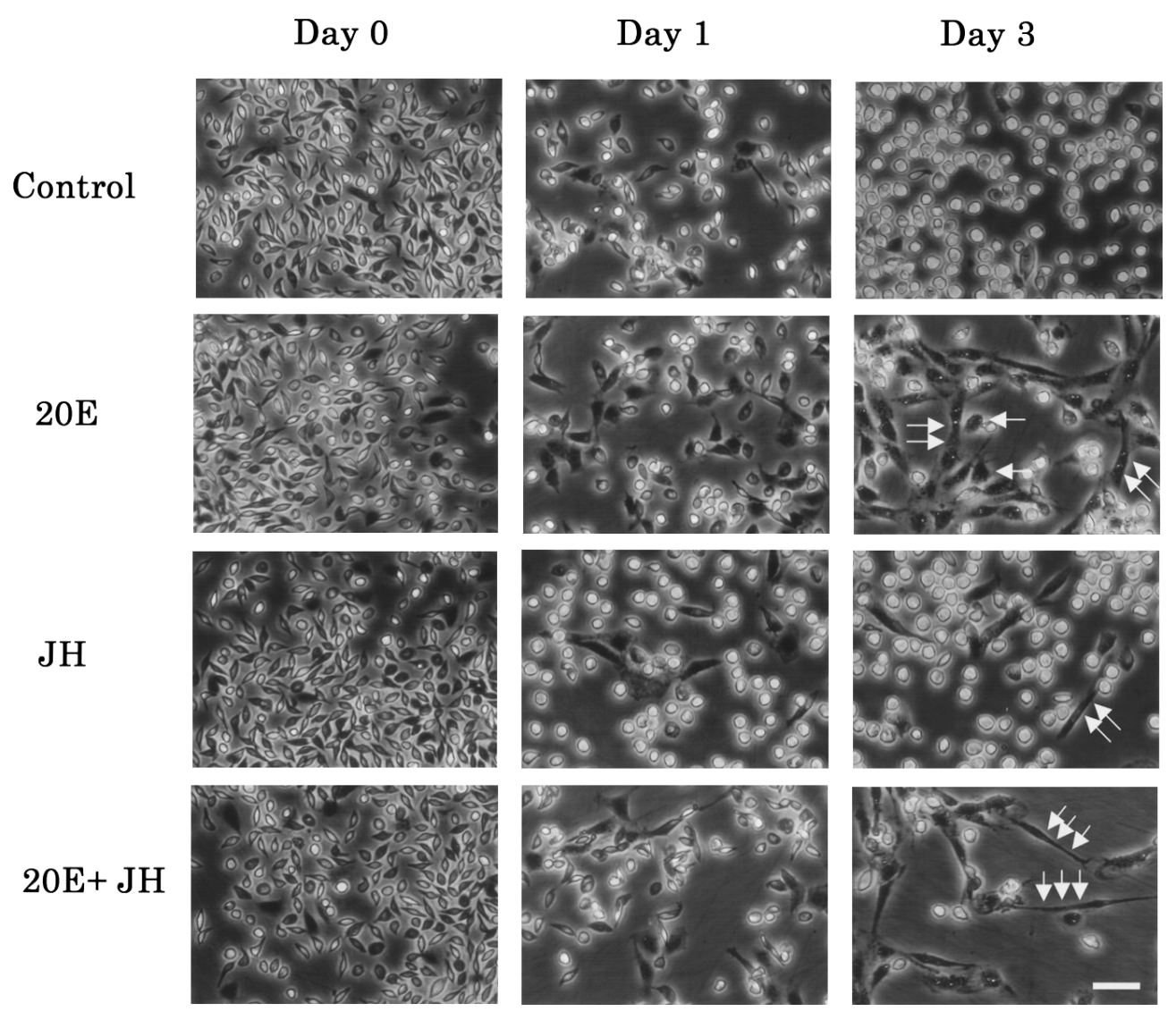

Fig. 2. X. pyrrhoderus hemocytes from late final instar larvae on days $0,1,3$ after the start of culture with media supplemented with insect hormones $\left(10^{-6} \mathrm{M}\right)$ : control, basal medium; 20E, 20-hydroxyecdysone; JH, juvenile hormone; 20E $+\mathrm{JH}, 20 \mathrm{E}$ and JH. Arrows indicate adherent spherical cells. Morphological changes of adherent cells were categorized based on the length of the longest axis of the cell: spherical cells (single arrow), 50-100 $\mu \mathrm{m}$, spindle-shaped cells (double arrows), over $100 \mu \mathrm{m}$, extended spindle-shaped cells (triple arrows). Bar indicates $50 \mu \mathrm{m}$.

mocytes were co-treated with $20 \mathrm{E}$ and $\mathrm{JH}$, the long-axis extension of spindle-shaped cells was remarkably increased (Figs. 2, 5), although the abundance of adherent cells and the total number of spindle-shaped cells were similar to those in the treatments of $20 \mathrm{E}$ alone (Figs. 3a, b, 5). The addition of $\mathrm{JH}$ one day before or after the treatment of $20 \mathrm{E}$ had effects on cell adhesion and morphological changes that were similar to those observed in the simultaneous treatment of $20 \mathrm{E}$ and $\mathrm{JH}$, suggesting that the order of treatment of these hormones was not crucial (Fig. 5).

We also examined whether JH-related compounds, all-trans retinoic acid and farnesol, act in conjunction with $20 \mathrm{E}$, as JH does. Neither all-trans retinoic acid nor farnesol had any effect. In addition, neither all-trans retinoic acid nor farnesol acted competitively with $\mathrm{JH}$ when these substances were co-treated with 20E and JH (Fig. 5).

\section{Response of prepupal hemocytes to insect hor- mones}

Responses of prepupal hemocytes at varying times between day 1 and 5 of the prepupal stage were investigated. The rate of adherent cells was significantly increased by $20 \mathrm{E}$ treatment from prepupal stage day 1 to day 2 (ANOVA, $p<0.01$ ) (Fig. 6 ). On the other hand, hemocytes obtained on and after day 3 of the prepupal stage had approximately $60 \%$ adherent hemocytes, irrespective of the hormone treatments (Fig. 6a). The changes in morphology observed in the 20E-induced adherent hemocytes from prepupal stage day 1 to day 3 (Fig. 6) were at similar levels as found in larval hemocytes (Fig. 3b). However, JH had little effect on the prepupal hemocytes. In hemocytes obtained on and after day 4 or day 5 of the prepupal stage, approximately $45 \%$ of the adherent hemocytes changed into spindle-shaped adherent cells, irrespective of 
a

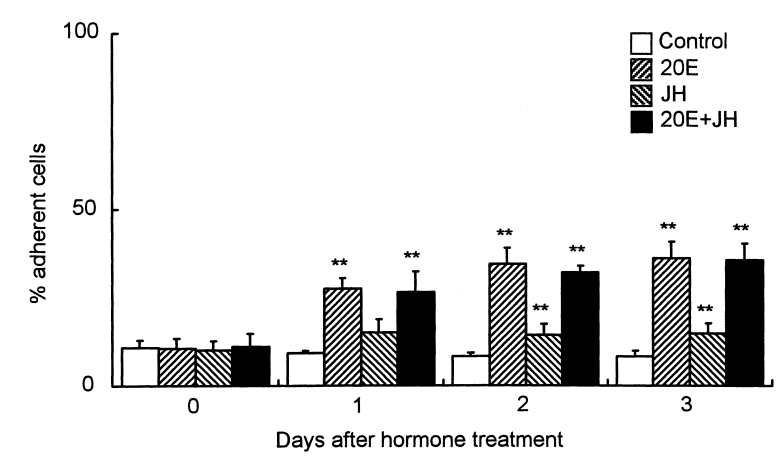

b

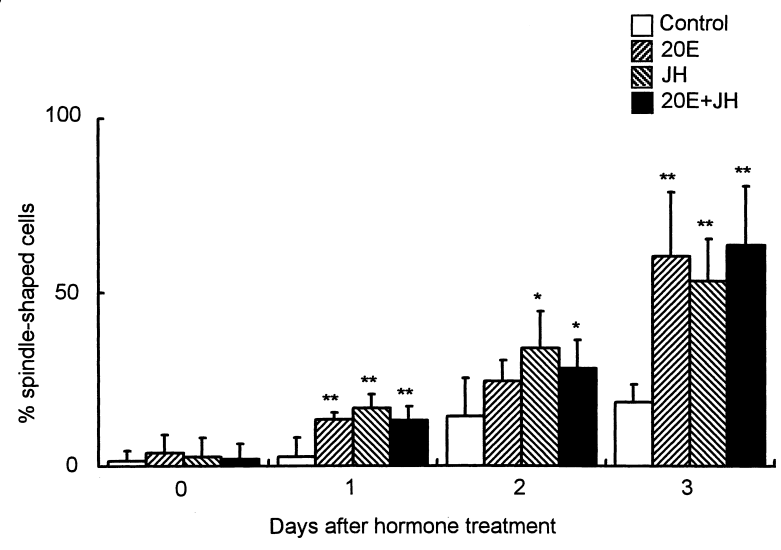

Fig. 3. In vitro time course of morphological changes in $X$. pyrrhoderus hemocytes from late final instar larvae: (a) hemocyte adhesion and (b) spindle-shaped cell formation. The following hormone treatments $\left(10^{-6} \mathrm{M}\right)$ were applied on day 0 : control, basal medium; 20E, 20-hydroxyecdysone; JH, juvenile hormone; $20 \mathrm{E}+\mathrm{JH}, 20 \mathrm{E}$ and $\mathrm{JH}$. Each value represents the mean $\pm \mathrm{SE}$ of 5 replicates. $* *: p<0.01$ (vs. control), *: $0.01<p<0.05$ (vs. control) by ANOVA. the hormone treatments. In prepupal hemocytes, an increase in the abundance of extended spindleshaped cells by the co-treatment of $20 \mathrm{E}$ and $\mathrm{JH}$ was observed only in hemocytes obtained at the early stages (day 1 to day 2) (data not shown).

\section{DISCUSSION}

Insect hemocytes play important roles in phagocytosis, encapsulation, nodule formation, and clotting of wounds (Wago, 1991; Ratcliffe, 1993; Lavine and Strand, 2002). When plasmatocytes and granulocytes of lepidopteran insects are seeded on culture plates, they adhere to the surface of the plates and spread. The results of the present study indicate that when $X$. pyrrhoderus larval hemo-

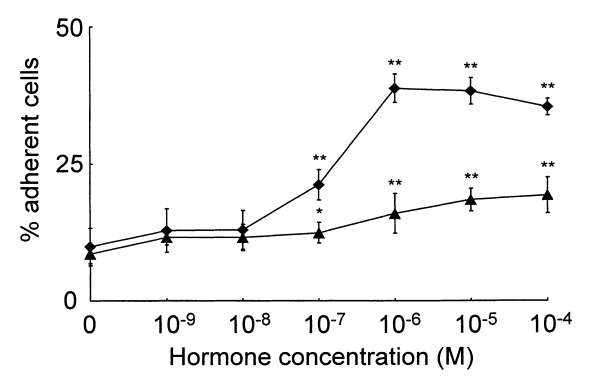

Fig. 4. Dose response curves of $20 \mathrm{E}(\boldsymbol{\bullet})$ and JH $(\boldsymbol{\Delta})$ on adhesion of hemocytes obtained from late final instar larvae of $X$. pyrrhoderus in vitro. Adherent cells were investigated on day 3 after 20E- or JH-treatment over the range of concentrations from $10^{-9}$ to $10^{-4} \mathrm{M}$. Each value represents the means $\pm \mathrm{SE}$ of 5 replicates. $* *: p<0.01$ (vs. control), *: $0.01<p<0.05$ (vs. control) by ANOVA.

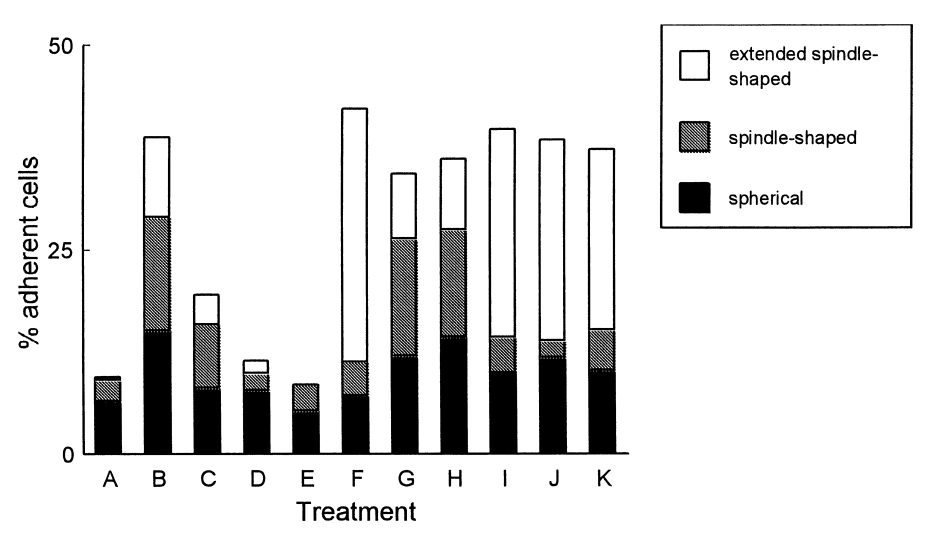

Fig. 5. Effects of 20E, JH, and JH-related compounds on the morphology of in vitro X. pyrrhoderus hemocytes from late final instar larvae. The morphology of the cells was categorized based on the length of the longest axis through the cell as spherical, less than $50 \mu \mathrm{m}$; spindle-shaped cells, $50-100 \mu \mathrm{m}$; and extended spindle-shaped cells, over $100 \mu \mathrm{m}$. The percent adherent cells and the morphology of the cells were investigated on day 3 of culture in media supplemented with the following compounds (10 $\left.{ }^{-6} \mathrm{M}\right)$ : $\mathrm{A}$, control (basal medium); B, 20E; C, JH; D, retinoic acid; E, farnesol; F, 20E+JH; G, 20E+retinoic acid; H, 20E+farnesol; I, JH treatment 1 day after treatment with $20 \mathrm{E} ; \mathrm{J}, 20 \mathrm{E}$ treatment 1 day after treatment with $\mathrm{JH} ; \mathrm{K}, 20 \mathrm{E}+\mathrm{JH}+$ retinoic acid + farnesol. 
a

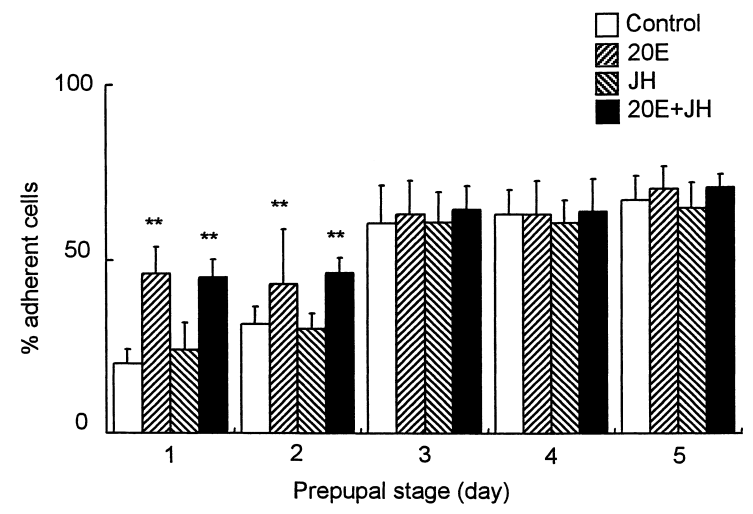

b

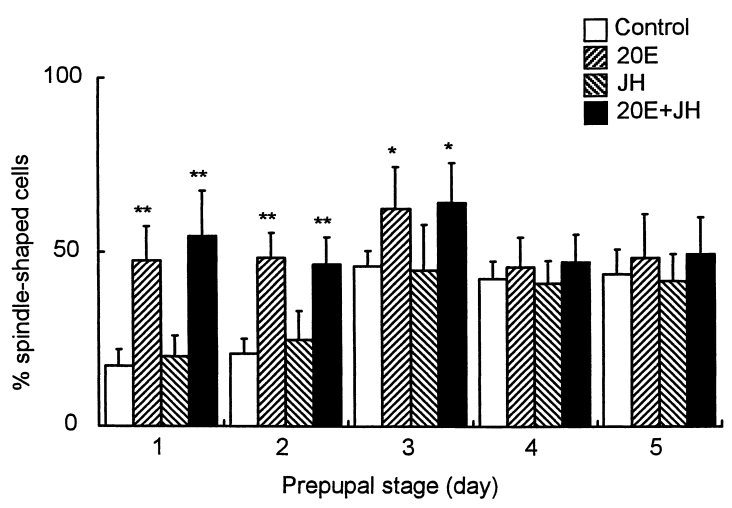

Fig. 6. Morphological changes in X. pyrrhoderus hemocytes from varying prepupal stages: (a) hemocyte adhesion and (b) spindle-shaped cell formation cultured in media with $10^{-6} \mathrm{M}$ of $20 \mathrm{E}$ and/or $\mathrm{JH}$. Investigations were carried out on day 3 cultures treated with the following hormone treatments $\left(10^{-6} \mathrm{M}\right)$ : control, basal medium; 20E, 20-hydroxyecdysone; $\mathrm{JH}$, juvenile hormone; $20 \mathrm{E}+\mathrm{JH}, 20 \mathrm{E}$ and $\mathrm{JH}$. Each value represents the means \pm SE of five replicates. ${ }^{* *}: p<0.01$ (vs. control), *: $0.01<p<0.05$ (vs. control) by ANOVA.

cytes are transferred into medium, $8.5 \%$ of the hemocytes adhere to the surface of the culture well, although the hemocyte types have not been classified in $X$. pyrrhoderus. Subsequently, some of the adherent hemocytes underwent a morphological change and became spindle-shaped. The rates of adherent and spindle-shaped cells increased during pupal transformation (Fig. $3 \mathrm{~b}$ and Fig. 6b). Changes in hemocytes during metamorphosis have been documented exclusively in holometabolous insects. A decrease in cell density and an increase in the ability to adhere in $X$. pyrrhoderus hemocytes at the premetamorphic stage agree with findings in other holometabolous insects (Arnold, 1952; Jones, 1956; Nittono, 1960). Since the hemocytes of lepidopteran and dipteran insects are found to be mixed with degenerated muscle and fat body tissues and phagocytose the tissue debris during metamorphosis, their ability to adhere to internal organs may be responsible for the observed decrease in cell density of circulating hemocytes (Akai, 1969; Crossley, 1968; Whitten, 1969).

Prepupal and pupal hemocytes have enhanced phagocytic activity to mammalian erythrocytes as well as to tissue debris (Wigglesworth, 1972). Metamorphic events associated with hemocytes generally require changes in the recognition system, including expression of scavenger receptors in hemocytes or loss of sialic acid in prothoracic glands for hemocyte adhesion (Karacali et al., 2000; Nishikawa and Natori, 2001). The mbn-2 cells established from Drosophila tumorous blood cells are capable of differentiating into adherent macrophage-like cells and simultaneously express scavenger receptor croquemort (crq) and dSR-C1 in response to addition of 20E (Dimarcq et al., 1997; Ress et al., 2000). Crq plays a specific role in phagocytosis of apoptotic corpses during embryogenesis, but also exists during metamorphosis (Franc et al., 1999; Bangs et al., 2000). Putative scavenger receptor is specifically expressed in pupal hemocytes of dipteran insects (Nishikawa and Natori, 2001). Thus, this scavenger function of hemocytes during metamorphosis must be evolutionarily developed in addition to the original immunological function.

The present study revealed that the hemocytes from $X$. pyrrhoderus larvae are responsive to $\mathrm{JH}$ as well as $20 \mathrm{E}$ in vitro. This is the first study to demonstrate the sensitivity of insect hemocytes to $20 \mathrm{E}$ and $\mathrm{JH}$. The most effective concentration $\left(10^{-6} \mathrm{M}\right)$ of $20 \mathrm{E}$ was shown to be similar to that of ecdysteroid titers in the hemolymph of other insect species prior to pupation (Dean et al., 1980; Nijhout, 1994). Irrespective of hormone treatment, hemocytes obtained from the mid-late prepupa stages showed high percentages of adhesion (Fig. 6), suggesting that the prepupal hemocytes of this stage had been exposed to a high concentration of ecdysteroids before the start of the experiment.

The effect of $\mathrm{JH}$ on hemocytes had not been studied to date. The present study showed that in response to $\mathrm{JH}, X$. pyrrhoderus larval hemocytes adhere and spread on the surface of culture plates to form spindle-shaped cells, although the response was weaker than that observed with the $20 \mathrm{E}$ treat- 
ment. While this effect of JH was not observed in prepupal hemocytes (Fig. 6), hemocytes from early final instar larvae responded to $\mathrm{JH}$ alone by adhering to the plate or undergoing morphological alteration into a floating flattened shape (Hoshino, unpublished). Thus, adherence of cells in $X$. pyrrhoderus larval hemocytes was shown to be sensitive to $\mathrm{JH}$, but the response became weaker with advancing stages of larval development. These data suggest that the action of $\mathrm{JH}$ on $X$. pyrrhoderus hemocytes may occur independently of $20 \mathrm{E}$. In contrast, both $20 \mathrm{E}$ and $\mathrm{JH}$ were necessary to alter the morphology of $X$. pyrrhoderus hemocytes into extended spindle-shaped cells (Fig. 5 ), suggesting that these hormones acted in a cooperative or dependent manner. It has been reported that $\mathrm{JH}$ rescues $\mathrm{Cl} 8+$ cells established from Drosophila wing disc from 20E-induced growth inhibition $24 \mathrm{~h}$ after 20E treatment (Cottam and Milner, 1998). However, the order of $20 \mathrm{E}$ and JH additions was not important to the alteration of hemocyte morphology in X. pyrrhoderus hemocytes (Fig. 5).

In holometabolous insects, JH titer falls to none level during the last larval instar but rises to a peak at the prepupal period, while ecdysteroid titer remains at a low level and then rises to one or two peaks during the last larval instar (Dean et al., 1980, Nijhout, 1994, 1999). The presence of JH during the prepupal period in holometabolous insects is known to contribute to normal development (Williams, 1961; Hiruma, 1980) and is crucial for the determination of pupal characters (Zhou and Riddiford, 2002). JH may also function in $X$. pyrrhoderus hemocytes at the premetamorphic stage. JH is generally known to counteract ecdysteroid. In $X$. pyrrhoderus, JH may act dependently or independently of $20 \mathrm{E}$ to induce morphological changes, which may differ with developmental age. Thus, X. pyrrhoderus hemocytes are shown to be affected by the endocrine system, and may have new characteristics for subsequent developmental stages.

Retinoic acid and farnesol possess structural similarities to JH (Hanley et al., 2000; Jones and Jones, 2000), but they do not have JH activities. Neither retinoic acid nor farnesol had an effect on $X$. pyrrhoderus hemocytes, either alone or with 20E. Thus, the effect of JHIII on $X$. pyrrhoderus hemocytes may be due to $\mathrm{JH}$ activity. JH was added to the basal medium at a predetermined concentration, however the actual concentration in the experiment must have been even lower because of its tendency to be absorbed by plastic (Giese et al., 1977).

The XP-1 cell line established from $X$. pyrrhoderus fat body tissues responds to $20 \mathrm{E}$ and $\mathrm{JH}$ by assuming a floating elongated-spindle shape and becoming strongly adherent, respectively (Iwabuchi, 1999). This cell line possesses the ability to phagocytose and has hemocyte-like electrophoretic characters (Iwabuchi and Hoshino, unpublished). Thus, an in vitro system with XP-1 cells and $X$. pyrrhoderus larval hemocytes may provide a valuable tool for analyzing hormonal regulations of insect, and in particular coleopteran, hemocytes during metamorphosis.

\section{REFERENCES}

Akai, H. (1969) Ultrastructure of haemocytes observed on the fat-body cells in Philosamia during metamorphosis. Jpn. J. Appl. Entomol. Zool. 13: 17-21 (in Japanese with English summary).

Arnold, J. W. (1952) The haemocytes of the Mediterranean flour moth, Ephestia kuhniella Zell. (Lepidoptera: Pyralididae). Can. J. Zool. 30: 352-364.

Bangs, P., N. Franc and K. White (2000) Molecular mechanisms of cell death and phagocytosis in Drosophila. Cell Death Differ. 7: 1027-1034.

Cottam, D. M. and M. J. Milner (1998) The effect of juvenile hormone on the response of the Drosophila imaginal disc cell line $\mathrm{Cl} 8+$ to moulting hormone. J. Insect Physiol. 44: $1137-1144$.

Crossley, A. C. (1968) The fine structure and mechanism of breakdown of larval intersegmental muscles in the blowfly Calliphora erythrocephala. J. Insect Physiol. 14: 1389-1407.

Dean, R. L., W. E. Bollenbacher, M. Locke, S. L. Smith and L. I. Gilbert (1980) Haemolymph ecdysteroid levels and cellular events in the intermoult/moult sequence of Calpodes ethlius. J. Insect Physiol. 26: 267-280.

Dimarcq, J-L., J-L. Imler, R. Lanot, A. B. Ezekowitz, J. A. Hoffmann, C. A. Janeway and M. Lagueux (1997) Treatment of 1(2)mbn Drosophila tumorous blood cells with the steroid hormone ecdysone amplifies the inducibility of antimicrobial peptide gene expression. Insect Biochem. Molec. Biol. 27: 877-886.

Duffy, E. A. J. (1952) A Monograph of the Immature Stages of British and Imported Timber Beetles (Cerambycidae). The British Museum (Natural History), London. 349 pp.

Franc, N. C., P. Heitzler, R. A. Ezekowitz and K. White (1999) Requirement for croquemort phagocytosis of apoptotic cells in Drosophila. Science 284: 1994-1998.

Giese, C., K. D. Spindler and H. Emmerrich (1977) The solubility of insect juvenile hormone in aqueous solutions 
and its absorption by glassware and plastics. Z. Naturforsch. 32: 158-160.

Han, S. S., M. H. Lee, T. Y. Yun and W. K. Kim (1995) Haemopoiesis in in vitro haemopoietic organ culture of Bombyx mori larvae. Korean J. Entomol. 25: 281-290.

Hanley, K., L. G. Komuves, D. C. Ng, K. Schoonjans, S. S. He, P. Lau, D. D. Bikle, M. L. Williams, P. M. Elias, J. Auwerx and K. R. Feingold (2000) Farnesol stimulates differentiation in epidermal keratinocytes via PPAR $\alpha$. J. Biol. Chem. 275: 11484-11491.

Hiruma, K. (1980) Possible roles of juvenile hormone in the prepupal stage of Mamestra brassicae. Gen. Comp. Endocrinol. 41: 392-399.

Hori, S., A. Kobayashi and S. Natori (2000) A novel hemocyte-specific membrane protein of Sarcophaga (flesh fly). Eur. J. Biochem. 267: 5397-5403.

Iwabuchi, K. (1999) An established cell line from the beetle, Xylotrechus pyrrhoderus (Coleoptera: Cerambycidae). In Vitro Cell Dev. Biol. Anim. 35: 612-615.

Jones, G. and D. Jones (2000) Considerations on the structural evidence of a ligand-binding function of ultraspiracle, an insect homolog of vertebrate RXR. Insect Biochem. Mol. Biol. 30: 681-689.

Jones, J. C. (1956) The hemocytes of Sarcophaga bullata Parker. J. Morphol. 99: 233-257.

Judy, K. J. and E. P. Marks (1971) Effects of ecdysterone in vitro on hindgut and hemocytes of Manduca sexta. Gen. Comp. Endocrinol. 17: 351-359.

Karacali, S., R. Deveci, S. Pehlivan and A. Ozcan (2000) Adhesion of hemocytes to desialylated prothoracic glands Galleria mellonella (Lepidoptera) in the larval stage. Invertebr. Reprod. Dev. 37: 167-170.

Kiger, J. A. Jr., J. E. Natzle and M. M. Green (2001) Hemocytes are essential for wing maturation in Drosophila malanogaster. Proc. Natl. Acad. Sci. USA 98: 1019010195.

Kremen, C. and H. F. Nijhout (1998) Control of pupal commitment in the imaginal disks of Precis coenia (Lepidoptera: Nymphalidae). J. Insect Physiol. 44: 287-296.

Kurata, S., H. Komano and S. Natori (1989) Dissociation of Sarcophaga perigrina (flesh fly) fat body by pupal haemocytes in vitro. J. Insect Physiol. 35: 559-565.

Kurata, S., H. Saito and S. Natori (1992) The 29 KDa hemocyte proteinase dissociates fat body at metamorphosis of Sarcophaga. Develop. Biol. 143: 115-121.

Lanot, R., D. Zachary, F. Holder and M. Meister (2001) Postembryonic hematopoiesis in Drosophila. Develop. Biol. 230: 243-257.

Lavine, M. D. and M. R. Strand (2002) Insect hemocytes and their role in immunity. Insect Biochem. Mol. Biol. 32: 1295-1309.

Mitsuhashi, J. and H. Inoue (1988) Obtainment of a continuous cell lines from larval fat bodies of the mulberry tiger moth, Spilosoma imparilis (Lepidoptera: Arctiidae). Appl. Entomol. Zool. 23: 488-490.

Nardi, J. B., C. Gao and M. R. Kanost (2001) The extracellular matrix protein lacunin is expressed by a subset of he- mocytes involved in basal lamina morphogenesis. J. Insect Physiol. 47: 997-1006.

Nardi, J. B. and M. Miklasz (1989) Hemocytes contribute to both the formation and breakdown of the basal lamina in developing wings of Manduca sexta. Tissue \& Cell 21: 559-567.

Nijhout, H. F. (1994) Insect Hormones. Princeton University Press, Princeton, New Jersey. 267 pp.

Nijhout, H. F. (1999) Hormonal control in larval development and evolution - insect. In The Origin and Evolution of Larval Forms (B. K. Hall ed.). Academic Press, San Diego, pp. 217-254.

Nishikawa, T. and S. Natori (2001) Targeted disruption of pupal hemocyte protein of Sarcophaga by RNA interference. Eur. J. Biochem. 268: 5295-5299.

Nittono, Y. (1960) Studies on the blood cells in the silkworm, Bombyx mori L. Bull. Seric. Exp. Sta. 16: 171266 (in Japanese).

Ratcliffe, N. A. (1993) Cellular defense responses of insects: unresolved problems. In Parasites and Pathogens of Insects. Vol. 1 (N. E. Beckage, S. N. Thompson and B. A. Federici eds.). Academic Press, San Diego, pp. 267304

Ress, C., M. Holtmann, U. Mass, J. Sofsky and A. Dorn (2000) 20-Hydroxyecdysone-induced differentiation and apoptosis in the Drosophila cell line, L(2)mbn. Tissue \& Cell 32: 464-477.

Riddiford, L. M. (1976) Hormonal control of insect epidermal cell commitment in vitro. Nature 259: 115-117.

Wago, H. (1991) Phagocytic recognition in Bombyx mori. In Immunology of Insects and Other Arthropods (A. P. Gupta ed.). CRC Press, Boca Raton, pp. 215-235.

Whitten, J. M. (1969) Haemocyte activity in relation to epidermal cell growth, cuticle secretion, and cell death in a metamorphosing cyclorrhaphan pupa. J. Insect Physiol. 15: 763-778.

Wigglesworth, V. B. (1959) Insect blood cells. Annu. Rev. Entomol. 4: 1-16.

Wigglesworth, V. B. (1972) The Principles of Insect Physiology. Chapman And Hall, London. 827 pp.

Wigglesworth, V. B. (1973) Haemocytes and basement membrane formation in Rhodnius. J. Insect Physiol. 19: 831-844.

Williams, C. M. (1961) The juvenile hormone. II. Its role in the endocrine control of moulting, pupation, adult development in the Cecropia silkworm. Biol. Bull. 121: $572-585$.

$\mathrm{Xu}$, Y-S. and H. Kawasaki (2001) Isolation and expression of cathepsin $\mathrm{B}$ cDNA in hemocytes during metamorphosis of Bombyx mori. Comp. Biochem. Physiol. B 130: 393-399.

Zhou, X. and L. M. Riddiford (2002) Broad specifies pupal development and mediates the status quo action of juvenile hormone on the pupal-adult transformation in Drosophila and Manduca. Development 129: 22592269. 